\title{
Hair-to-blood ratio and biological half-life of mercury: experimental study of methylmercury exposure through fish consumption in humans
}

\author{
Kozue Yaginuma-Sakurai1 ${ }^{1,2}$, Katsuyuki Murata ${ }^{3}$, Miyuki Iwai-Shimada',2, Kunihiko Nakai', \\ Naoyuki Kurokawa ${ }^{1}$, Nozomi Tatsuta ${ }^{1}$ and Hiroshi Satoh ${ }^{1}$ \\ ${ }^{1}$ Environmental Health Sciences, Tohoku University Graduate School of Medicine, 2-1 Seiryo-machi, \\ Aoba-ku, Sendai 980-8575, Japan \\ ${ }^{2}$ Research Fellow of the Japan Society for the Promotion of Science, 8 Ichiban-cho, Chiyoda-ku, \\ Tokyo 102-8472, Japan \\ ${ }^{3}$ Department of Environmental Health Sciences, Akita University Graduate School of Medicine, 1-1-1 Hondo, \\ Akita 010-8543, Japan
}

(Received September 30, 2011; Accepted November 12, 2011)

\begin{abstract}
The hair-to-blood ratio and biological half-life of methylmercury in a one-compartment model seem to differ between past and recent studies. To reevaluate them, 27 healthy volunteers were exposed to methylmercury at the provisional tolerable weekly intake $(3.4 \mu \mathrm{g} / \mathrm{kg}$ body weight $/$ week $)$ for adults through fish consumption for 14 weeks, followed by a 15 -week washout period after the cessation of exposure. Blood was collected every 1 or 2 weeks, and hair was cut every 4 weeks. Total mercury ( T-Hg) concentrations were analyzed in blood and hair. The T-Hg levels of blood and hair changed with time $(p<0.001)$. The mean concentrations increased from $6.7 \mathrm{ng} / \mathrm{g}$ at week 0 to $26.9 \mathrm{ng} / \mathrm{g}$ at week $14 \mathrm{in}$ blood, and from 2.3 to $8.8 \mu \mathrm{g} / \mathrm{g}$ in hair. The mean hair-to-blood ratio after the adjustment for the time lag from blood to hair was $344 \pm 54$ (S.D.) for the entire period. The half-lives of T-Hg were calculated from raw data to be $94 \pm 23$ days for blood and $102 \pm 31$ days for hair, but the half-lives recalculated after subtracting the background levels from the raw data were $57 \pm 18$ and $64 \pm 22$ days, respectively. In conclusion, the hair-to-blood ratio of methylmercury, based on past studies, appears to be underestimated in light of recent studies. The crude half-life may be preferred rather than the recalculated one because of the practicability and uncertainties of the background level, though the latter half-life may approximate the conventional one.
\end{abstract}

Key words: Methylmercury, Biological half-life, Blood-to-hair concentration ratio, Kinetics, Experimental study

\section{INTRODUCTION}

Methylmercury $(\mathrm{MeHg})$ is well known to be a widespread environmental neurotoxicant to which we are exposed mainly via fish consumption (National Research Council, 2000; WHO, 1990). As the developmental effects of prenatal exposure are of great concern (Grandjean et al., 1997, 2004; Strain et al., 2008; Suzuki et al., 2010), recommendations for the amount of $\mathrm{MeHg}$ intake were proposed by the Joint Food and Agriculture Organization/World Health Organization Expert Committee on Food Additives (JECFA, 2003) and the
Japan Food Safety Commission (2005) as the provisional tolerable weekly intake (PTWI) of $1.6 \mu \mathrm{g}$ of mercury/ $\mathrm{kg}$ body weight $(\mathrm{BW}) /$ week and tolerable weekly intake (TWI) of $2.0 \mu \mathrm{g}$ of mercury $/ \mathrm{kg} \mathrm{BW} /$ week for pregnant women, respectively. In the calculation of PTWI/TWI, however, various assumptions (e.g., the hair-to-blood ratio of 250 and elimination constant of 0.014 ) and different uncertainty factors for interpersonal pharmacokinetic variability have been utilized, but the former values seem to differ between past and recent studies. For endorsing the validity of such assumptions, it is crucial to reevaluate the kinetics of $\mathrm{MeHg}$ transfer in human blood and hair.

Correspondence: Hiroshi Satoh (E-mail: h.satoh@ehs.med.tohoku.ac.jp) 
Some experimental studies of the $\mathrm{MeHg}$ kinetics in humans were conducted several decades ago (Aberg et al., 1969; Birke et al., 1972; Hislop et al., 1983; Kershaw et al., 1980; Miettinen et al., 1971; Sherlock et al., 1984; Smith et al., 1994). The exposure settings of those studies may differ from our current state in general, i.e. longterm exposure at low levels. In addition, the hair-to-blood mercury concentration ratio shows wide variation in not only animal experiments (Mottet et al., 1987) but also epidemiological studies (Berglund et al., 2005; BudtzJørgensen et al., 2004). However, no one has revised the above conventional assumptions. To scrutinize the hairto-blood ratio and biological half-life of mercury, we conducted an experimental study on low-level exposure to $\mathrm{MeHg}$ in humans.

\section{MATERIALS AND METHODS}

\section{Subjects}

Twenty-seven healthy volunteers (14 men and 13 women) were recruited among students and graduates of universities in Sendai, Japan. The main exclusion criteria of this study were obvious diseases such as heart, neurological and metabolic disorders and, for women, confirmed or suspected pregnancy, intended pregnancy and nursing. All subjects were provided with a complete study protocol, and gave written informed consent for participation.

\section{Study protocol}

The study protocol was approved by the Ethics Committee of the Tohoku University Graduate School of Medicine. The detailed method and design were described previously (Yaginuma-Sakurai et al., 2010). Although a control group unexposed to $\mathrm{MeHg}$ was set up in that study, only the subjects of the experimental group were analyzed in the present study. The subjects of the experimental group were exposed to $\mathrm{MeHg}$ at the PTWI for Japanese adults $(3.4 \mu \mathrm{g} / \mathrm{kg} \mathrm{BW} /$ week) from the consumption of bigeye tuna and swordfish, containing approximately $1.0 \mu \mathrm{g} / \mathrm{g} \mathrm{MeHg}$, during the initial 14-week period (the exposure period), and after that, observation continued for another 15 weeks (the washout period). The amount of fish consumption was calculated on the basis of each subject's BW (e.g., a subject whose BW was $60 \mathrm{~kg}$ consumed $204 \mathrm{~g} /$ week of bigeye tuna or swordfish). A mean of 210 (range, 131 310) g of fish was given to each subject once a week. No restriction was placed on the cooking method because frying, boiling or steaming of fish does not lead to any significant loss of $\mathrm{MeHg}$ (Sherlock et al., 1984). Consumption of fish containing high levels of $\mathrm{MeHg}$ was restricted during the whole period of 29 weeks.
Blood was collected every week during the exposure period and every 2 weeks during the washout period. After the blood was collected and the hematocrit measured, the blood was centrifuged for $5 \mathrm{~min}$ at $12,000 \mathrm{rpm}$. Until mercury analysis, separated red blood cells (RBCs) and plasma were stored at $-80^{\circ} \mathrm{C}$. Hair growing newly was cut close to the scalp in the same $1 \mathrm{~cm} \times 1 \mathrm{~cm}$ square of the occipital area every 4 weeks, and the median length in the hair rearranged from the shortest to the longest one was measured as the growth rate. The hair samples were kept in a desiccator until mercury analysis. Since artificial hair-waving and hair-straightening may affect the total mercury (T-Hg) level in hair (Dakeishi et al., 2005; Ohba et al., 2008), they were banned during the whole period of this study.

\section{Measurements}

Analysis of the T-Hg content of RBCs, plasma and hair was carried out by cold vapor atomic absorption spectrometry according to the method of Akagi and Nishimura (1991). The samples were acid digested with $\mathrm{HNO}_{3}$, $\mathrm{HClO}_{4}$, and $\mathrm{H}_{2} \mathrm{SO}_{4}$ at $200^{\circ} \mathrm{C}$ for $30 \mathrm{~min}$. The resultant ionic mercury was then reduced to mercury vapor by adding $\mathrm{SnCl}_{2}$ to a flameless atomic absorption monitor (HG-201 Sanso Co., Ltd., Tokyo, Japan). The T-Hg concentration in whole blood $(W, \mathrm{ng} / \mathrm{g})$ was calculated from the formula: $W=R \times H / 100+P \times(1-H / 100)$, where $H$ is the hematocrit and $R$ and $P$ are the concentrations in RBCs (ng/g) and plasma (ng/g), respectively. T-Hg analyses of RBCs and plasma were conducted by IDEA Consultants, Inc. (Tokyo, Japan). The analysis of blood samples was conducted after the samples were arranged at random to avoid systematic bias.

Accuracy of determination was confirmed by using certified reference materials. Human blood material (Seronorm trace elements whole blood level-2 201605 and serum level-1 201405; SERO AS, Billingstad, Norway) was used for T-Hg in RBCs and plasma, and human hair material (NIES CRM No.13; National Institute for Environmental Studies; Ibaraki, Japan) was used for $\mathrm{T}-\mathrm{Hg}$ in hair. The determined value (mean \pm S.D.), for T-Hg in Seronorm 201605 was $7.86 \pm 0.49 \mathrm{ng} / \mathrm{ml}$ ( $n=28$; certified value $7.4 \sim 10.0 \mathrm{ng} / \mathrm{ml}$ ), that for T-Hg in Seronorm 201405 was $1.01 \pm 0.11 \mathrm{ng} / \mathrm{ml}(n=24 ; 0.9 \sim$ $1.3 \mathrm{ng} / \mathrm{ml})$, and the T-Hg level in NIES CRM No. 13 was $4.46 \pm 0.14 \mu \mathrm{g} / \mathrm{g}(n=27 ; 4.42 \pm 0.20 \mu \mathrm{g} / \mathrm{g})$.

\section{Statistical analysis}

The time-dependent changes of $\mathrm{T}-\mathrm{Hg}$ concentrations of whole blood and hair and the hair-to-blood T-Hg concentration ratio were tested by two-way analysis of vari- 
Kinetics of methylmercury in humans

Table 1. Characteristics of the study subjects (14 men and 13 women) at week 0

\begin{tabular}{lcc}
\hline Characteristics & Mean \pm S.D. & Range \\
\hline Age (year) & $25.2 \pm 4.1$ & $(20 \sim 35)$ \\
Body mass index $\left(\mathrm{kg} / \mathrm{m}^{2}\right)$ & $22.2 \pm 3.2$ & $(17.6 \sim 30.5)$ \\
Hematocrit $(\%)$ & $43.2 \pm 3.9$ & $(36 \sim 50)$ \\
Total mercury in red blood cells $(\mathrm{ng} / \mathrm{g})$ & $13.5 \pm 6.4$ & $(7.4 \sim 39.7)$ \\
Total mercury in plasma $(\mathrm{ng} / \mathrm{g})$ & $1.4 \pm 0.5$ & $(0.5 \sim 2.8)$ \\
Total mercury in whole blood $(\mathrm{ng} / \mathrm{g})$ & $6.7 \pm 3.3$ & $(3.2 \sim 19.8)$ \\
Total mercury in hair $(\mu \mathrm{g} / \mathrm{g})$ & $2.3 \pm 1.1$ & $(1.1 \sim 6.5)$ \\
Ratio of hair to blood total mercury & $351 \pm 54$ & $(263 \sim 478)$ \\
\hline
\end{tabular}

ance (ANOVA) to control for interpersonal variations and by a trend test using the cumulative $\chi^{2}$ method because they were regarded as an approximately normal distribution (Hosmer-Lemeshow test, $p>0.1$ ). The difference between two slopes of the increasing changes in whole blood and hair was tested by ANOVA (Snedecor and Cochran, 1967). All statistical analyses, with two-sided $p$ values, were performed using the Statistical Package for the Biosciences (Murata and Yano, 2002) and the statistical significance was set at $p<0.05$.

\section{RESULTS}

The characteristics of the 27 subjects at week 0 are summarized in Table 1. The participants had neither weight loss nor subjective symptoms during the whole period of 29 weeks, and the laboratory data for blood pressure, liver function, total cholesterol, triglycerides, and hemoglobin were within the normal ranges (YaginumaSakurai et al., 2010). Although the interpersonal variation in hematocrit was significantly large (ANOVA, $p<0.001)$, no significant changes in the hematocrit were seen during the entire period of 29 weeks $(p>0.2)$. The mean $\mathrm{T}-\mathrm{Hg}$ level in whole blood was significantly higher for men $(8.0 \pm 4.0 \mathrm{ng} / \mathrm{g})$ than for women $(5.3 \pm 1.5 \mathrm{ng} / \mathrm{g})$ (Student $t$ test, $p<0.05$ ); but, there was no significant sex difference either in the hair-to-blood ratio $(p>0.2)$ or biological half-lives in blood $(p>0.8)$ and hair $(p>0.6)$. Hence, the statistical analyses were conducted without separating the subjects by sex. Most of the subjects $(81.6 \%)$ ate the bigeye tuna/swordfish twice or three times a week, by dividing it into two or three portions. Similarly, $14.2 \%$ of them ate it in one helping, and the remaining did so in four or five. They also consumed other fish containing low levels of $\mathrm{MeHg}$ a mean of 1.0 (range, $0 \sim 5$ ) times a week during the exposure period, and a mean of 1.3 (range, $0 \sim 6$ ) times a week during the washout period.

Temporal patterns of T-Hg levels in whole blood and hair of the 27 subjects are presented in Fig. 1. The blood $\mathrm{T}-\mathrm{Hg}$ level changed significantly with time $(p<0.001)$. The trend test showed that the increasing trend in the period from weeks 0 to 14 and the decreasing trend in the period from weeks 14 to 29 were statistically significant ( $F=262, p<0.001$ and $F=108, p<0.001$, respectively). The T-Hg level at week 0 was $6.7 \pm 3.3 \mathrm{ng} / \mathrm{g}$. It reached the maximum $(26.9 \pm 6.8 \mathrm{ng} / \mathrm{g})$ at week 14 (i.e., the last week of the exposure period), and decreased to $11.9 \pm 4.2 \mathrm{ng} / \mathrm{g}$ at week 29. Similarly, the hair T-Hg level changed significantly with time $(p<0.001)$, increasing from $2.3 \pm 1.1 \mu \mathrm{g} / \mathrm{g}$ (week 0$)$ to $8.8 \pm 2.0 \mu \mathrm{g} / \mathrm{g}$ (week 17) $(F=233, p<0.001$ by the trend test), and then decreasing to $4.9 \pm 1.6 \mu \mathrm{g} / \mathrm{g}$ (week 29$)(F=40.8, p<0.001)$. The slopes of increasing trends in the 27 subjects were $1.39 \mathrm{ng} / \mathrm{g} /$ week in whole blood and $0.498 \mu \mathrm{g} / \mathrm{g} /$ week in hair, and the two slopes differed significantly $(F=71.7$, $p<0.001)$.

The mean and median concentration ratios of hair-toblood T-Hg, calculated using hair and blood samples collected at the same time (i.e., unadjusted ratios), are shown in Fig. 1 and Table 2. The ratios changed significantly with time $(F=180, p<0.001)$. The mean ratio ( \pm S.D.) for the entire period was $345 \pm 102$ (median 356), and the 5th and 95th percentiles were 176 and 492, respectively. Next, since the time lag (i.e., the time to transfer mercury) from blood to hair on the scalp was estimated to be 3 weeks from the rising slope of hair T-Hg (YaginumaSakurai et al., 2010), the adjusted hair-to-blood ratios were calculated by means of interpolation. The mean value for the entire period was $344 \pm 54$ (median 343), and the 5 th and 95th percentiles were 260 and 447, respectively. Although the adjusted ratio changed significantly with time $(F=19.4, p<0.001)$, the S.D. of the adjusted ratios for the entire period became smaller than that of the 
K. Yaginuma-Sakurai et al.

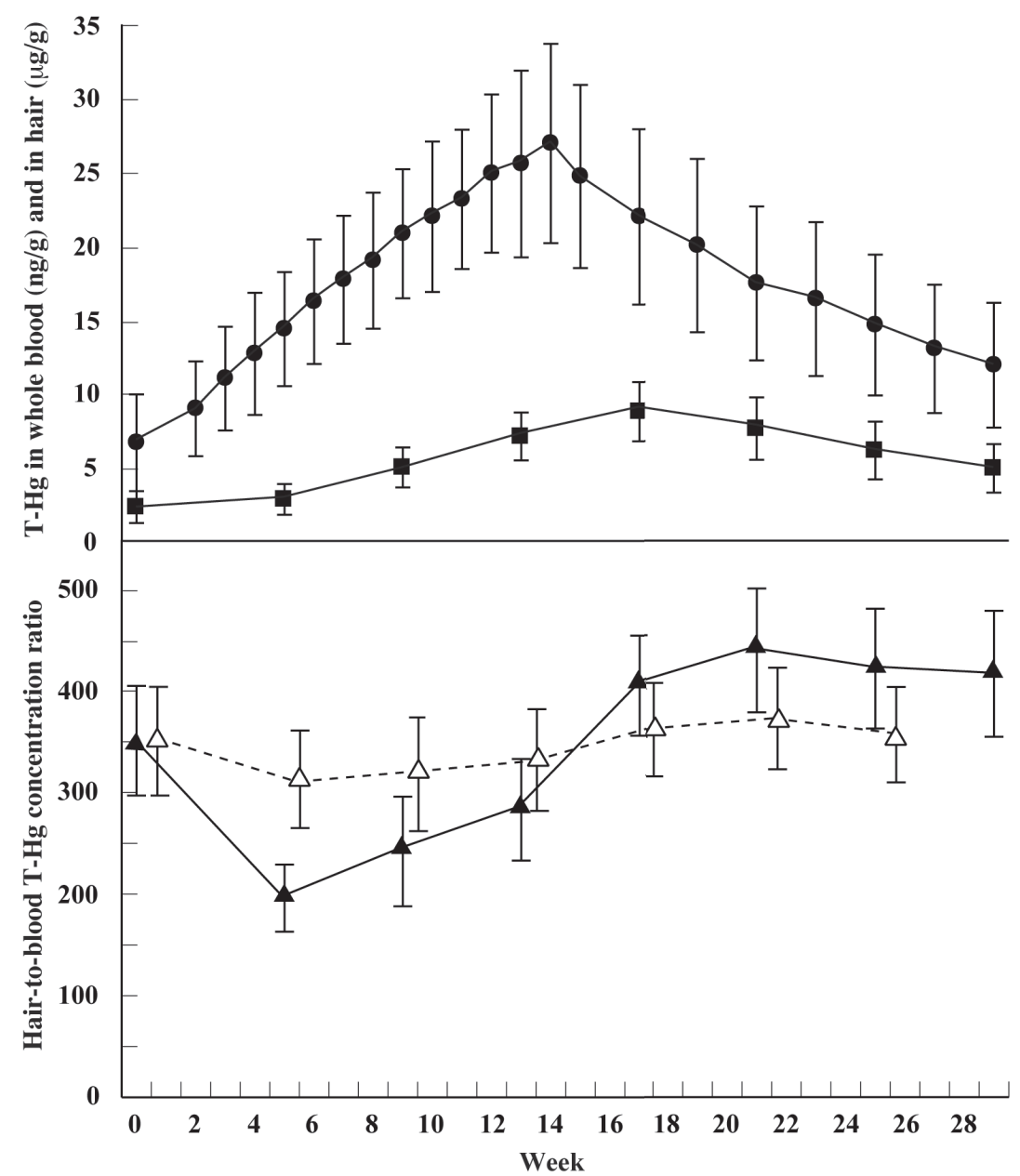

Fig. 1. Temporal changes of total mercury (T-Hg) concentrations in whole blood $(\bullet)$ and hair $(\mathbf{\square})$ and of hair-to-blood T-Hg concentration ratios in 27 subjects (mean and SD). The symbols of $\Delta$ and $\boldsymbol{\Delta}$ represent the time lag-adjusted and unadjusted hair-to-blood ratios, respectively.

Table 2. Unadjusted and adjusted ratios of the hair-to-blood total mercury concentrations in 27 subjects

\begin{tabular}{|c|c|c|c|c|}
\hline \multirow{2}{*}{ Week } & \multicolumn{2}{|c|}{ Unadjusted ratios } & \multicolumn{2}{|c|}{ Adjusted ratios* } \\
\hline & Median & (5 and 95 percentiles) & Median & (5 and 95 percentiles) \\
\hline 0 & 354 & $(267,475)$ & 354 & $(267,475)$ \\
\hline 5 & 194 & $(139,249)$ & 315 & $(244,413)$ \\
\hline 9 & 241 & $(144,375)$ & 303 & $(225,443)$ \\
\hline 13 & 279 & $(212,396)$ & 321 & $(264,451)$ \\
\hline 17 & 399 & $(316,512)$ & 353 & $(294,474)$ \\
\hline 21 & 433 & $(344,571)$ & 370 & $(300,489)$ \\
\hline 25 & 421 & $(335,551)$ & 352 & $(287,472)$ \\
\hline 29 & 411 & $(300,569)$ & & \\
\hline
\end{tabular}

\footnotetext{
* In these ratios, total mercury concentrations in hair were adjusted for the time lag from blood to hair on the scalp ( 3 weeks) by using interpolation.
} 
Kinetics of methylmercury in humans

Table 3. Biological half-lives of mercury in whole blood and hair calculated from three types of data*

\begin{tabular}{|c|c|c|c|c|}
\hline \multirow{2}{*}{ Biological half-lives } & \multicolumn{2}{|c|}{ Whole blood $^{+}$} & \multicolumn{2}{|c|}{ Hair $^{+}$} \\
\hline & Mean \pm S.D. & Range & Mean \pm S.D. & Range \\
\hline \multicolumn{5}{|l|}{ Crude half-life } \\
\hline Background value $\times 0$ & $94 \pm 23$ & $(58 \sim 155)$ & $102 \pm 31$ & $(60 \sim 192)$ \\
\hline \multicolumn{5}{|c|}{ Recalculated half-life after subtracting the below background values from the raw values } \\
\hline Background value $\times 0.5$ & $76 \pm 18$ & $(42 \sim 122)$ & $83 \pm 24$ & $(46 \sim 138)$ \\
\hline Background value $\times 1$ & $57 \pm 18$ & $(22 \sim 112)$ & $64 \pm 22$ & $(14 \sim 126)$ \\
\hline
\end{tabular}

unadjusted ones.

The elimination of $\mathrm{T}-\mathrm{Hg}$ can be expressed as a single exponential function, and the concentration $(C)$ in an organ at any time $(t)$ is as follows (Task Group on Metal Accumulation, 1973; WHO, 1976): $C=C_{0} \times e^{-b \cdot t}$, where $C_{0}$ and $b$ are the initial concentration in the organ and the elimination constant, respectively. The relation between the elimination constant and the biological half-life $(T)$ is: $T=\ln 2 / b$, where $\ln 2$ (natural logarithm of 2 ) is 0.693 . Table 3 presents the mean half-lives calculated from three background levels (i.e., $\times 0, \times 0.5$, and $\times 1$ ) to examine the impact of a certain background level. The mean half-lives calculated from raw data (i.e., not using background levels) of the 27 subjects were $94 \pm 23$ days in whole blood and $102 \pm 31$ days in hair. The crude half-life in whole blood was significantly shorter than that in hair (pairedsample $t$ test, $p<0.01$ ). On the other hand, the half-lives, recalculated after subtracting the background level (i.e., the $\mathrm{T}-\mathrm{Hg}$ concentration at week 0 ) from the actual $\mathrm{T}-\mathrm{Hg}$ concentrations in the decreasing phase of this experiment, were $57 \pm 18$ days in whole blood and $64 \pm 22$ days in hair, and gradually became shorter according to subtraction of the background level (Table 3).

\section{DISCUSSION}

This is the most recent report examining the kinetics of mercury on the basis of an experimental study. As stated in our previous paper (Yaginuma-Sakurai et al., 2010), the exposure procedure was successfully achieved and no participants had weight loss or any symptoms such as tremor or finger numbness during the whole period of 29 weeks. As shown in Fig. 1, fish consumption at the PTWI level for 14 weeks elevated the $\mathrm{T}-\mathrm{Hg}$ concentrations in whole blood and hair, though the exposure duration of $\mathrm{MeHg}$ was not long enough to reach a steady state. Under the hypothetical steady-state condition, the blood mercury level will be estimated to be $18.3 \mathrm{ng} / \mathrm{g}$ by substituting the $\mathrm{MeHg}$ intake of $3.4 \mu \mathrm{g} / \mathrm{kg} \mathrm{BW} /$ week into a onecompartment pharmacokinetic model (National Research Council, 2000), and the mercury level in hair will be 4.6 $\mu \mathrm{g} / \mathrm{g}$ by using the hair-to-blood concentration ratio of 250 , which was established in a study of various populations exposed to MeHg at fairly constant levels (JECFA, 2003; US EPA, 2001; WHO, 1990). However, the observed values of increments in our study were considerably higher than the above expected ones. This disagreement implies that some constants of the pharmacokinetic model may not be appropriate.

All the median ratios of the time lag-adjusted/unadjusted hair-to-blood $\mathrm{T}-\mathrm{Hg}$, except those at the 5 th and 9th weeks, exceeded 250 as shown in Table 2, whereas the published ratios lay within the range of $140 \sim 370$ (JECFA, 2003). The median ratios in Faroese children were 370 at 7 years of age and 264 at 14 years (BudtzJørgensen et al., 2004). Sakamoto et al. (2007) reported that the average hair-to-blood ratio in Japanese pregnant women was about 350 , probably because of the lower hematocrit during gestation. The median ratio in Swedish men and women was 373 (Berglund et al., 2005). Taken together, these data suggest that the previous ratio of 250 , used for calculation of the PTWI/TWI (Japan Food Safety Commission, 2005; JECFA, 2003) and tolerable daily intake (National Research Council, 2000), is too small compared with the recent ones. In the advanced world of science and technology, further discussion is required to decide whether the hair-to-blood ratio of $\mathrm{MeHg}$ should be raised to around 350 on the basis of these recent data, not the conventional ones.

As can be seen in Table 2 and Fig. 1, the unadjusted hair-to-blood T-Hg concentration ratio declined briefly during the 14-week period of bigeye tuna/swordfish 
intake. A similar finding has been shown by a cross-sectional study reporting that the hair-to-blood ratio seemed to decrease with increasing $\mathrm{MeHg}$ in blood due to more frequent fish consumption (Berglund et al., 2005). This could be accounted for by the fact that the rise of $\mathrm{T}-\mathrm{Hg}$ during the exposure period is faster in whole blood than in hair, as proven both by the present study and by another study using toxicokinetic model simulations (Gosselin et al., 2006). The temporal decline of the ratio adjusted for the time lag of 3 weeks was indeed minimized as compared to the unadjusted ratio. Similarly, a wide range of hair-to-blood ratios can be explained by the time lag; that is, most of the previous studies may not have considered this effect in calculating the hair-to-blood ratio, and the frequency of fish consumption is very changeable seasonally (Murata et al., 2007). As a result, the uncertainty factor relevant to risk management of $\mathrm{MeHg}$ should be lessened based on this evidence, although it differs among several organizations for risk management (EFSA, 2004; Japan Food Safety Commission, 2005; JECFA, 2003; Legrand et al., 2010; US EPA, 2001).

The biological half-lives of $\mathrm{T}-\mathrm{Hg}$ calculated from raw data of this study were approximately 100 days, and the elimination constant would become half of the current one (i.e., $\ln 2 / 50)$. If this crude half-life is considered to be too long, it may have been attributable partly to fish consumption during the washout period after the cessation of exposure. Actually, our restriction of fish consumption was not so strict and some of our subjects ate a small amount of fish containing low levels of $\mathrm{MeHg}$, such as sardines, salmon, and eel, during the washout period, while their docosahexaenoic and eicosapentaenoic acids in plasma gradually, but not significantly, decreased from $141 \mu \mathrm{g} / \mathrm{ml}$ at week 0 to $115 \mu \mathrm{g} / \mathrm{ml}$ at week 29 (YaginumaSakurai et al., 2010). At least, the minimum values for the crude half-lives of the 27 subjects were 58 days for whole blood and 60 days for hair, and therefore more than the 50-day conventional value.

In contrast, the mean half-lives of $\mathrm{T}-\mathrm{Hg}$, recalculated after subtracting the background $\mathrm{T}-\mathrm{Hg}$ concentration, were 57 days for whole blood and 64 days for hair, which may be apparently accordant with past studies. Kershaw et al. (1980) and Sherlock et al. (1984) reported that the mean half-lives of T-Hg in whole blood of volunteers exposed to high doses of $\mathrm{MeHg}$ from fish consumption were $52 \pm 4$ (S.E.) days (mean dose of $20.0 \mu \mathrm{g} / \mathrm{kg} \mathrm{BW} /$ day) and $50 \pm 1$ days $(1.6 \mu \mathrm{g} / \mathrm{kg} \mathrm{BW} /$ day), respectively, whereas Smith and Farris (1996) obtained a half-life of 44 days from other data. However, the formula $C=C_{0}$ $\times e^{-b \cdot t}$ does not specify that the elimination constant $(b)$ should be calculated after subtracting the background level from $C_{0}$ and $C$ (Al-Shahristani et al., 1976; WHO, 1976); because, the background levels are uncertain in most cases. For instance, the fact that the average blood lead levels of American populations in 1976-1980 were considerably high, i.e. $10 \sim 15 \mu \mathrm{g} / \mathrm{dl}$ as the background level (Mahaffey et al., 1982), may be cited. Most human studies using an isotope-labeled metal (Aberg et al., 1969; Miettinen et al., 1971; Smith et al., 1994) ignored the background levels or did not exactly present them. Rather, the above formula initially must have been practical in light of the background uncertainties (Rabinowitz et al., 1976). Thus, the half-life of mercury was suggested to be longer than we expected.

In the present study, the crude/recalculated half-life of $\mathrm{T}-\mathrm{Hg}$ was significantly longer in hair than in whole blood. In past studies, the half-life in whole blood was around 50 days (Stern, 2005), as mentioned above. The average half-life in hair was calculated to be 72 (range, 35 to 189) days in Iraqi patients with high blood levels of T-Hg (Al-Shahristani and Shihab, 1974), and that in hair was 80 (33 to 120) days in volunteers having high $\mathrm{MeHg}$ intakes from fish (Birke et al., 1972). In any case, the half-life of mercury is organ-dependent, similar to other metals such as lead.

Concerning factors influencing the half-life of mercury, we showed that subtraction of the background level modified the half-life drastically (Table 3), though it is debatable whether such subtraction is necessary. Stern (2005) reported that the mean half-lives of four studies increased with increasing $\mathrm{MeHg}$ doses, i.e. there was a positive correlation between the exposure dose and half-life, but our crude/recalculated half-lives under the exposure dose of $0.486 \mu \mathrm{g} / \mathrm{kg} \mathrm{BW} /$ day did not seem to correspond with that result. Apart from the half-life of mercury, O'Flaherty et al. (1982) found that the half-life of blood lead was positively correlated both with pre-strike blood lead (initial dose) and the duration of lead exposure in 68 primary smelters. However, they thought that the dependence of half-life on pre-strike blood lead was a reflection of interpersonal differences in lead kinetics, and only the direct dependence of half-life on duration of lead exposure was stressed. Although the compartment model differs somewhat between lead and mercury, the mode of exposure, e.g. one-shot, short-term, or long-term exposure, may affect the half-life.

In our study, there may have been some potential limitations. For instance, the hair growth rate might be affected by race, sex, age, and season. In fact, the hair growth rate (about $1.4 \mathrm{~cm} / \mathrm{month}$ ) in Japanese subjects (YaginumaSakurai et al., 2010) differed from those $(0.8 \sim 1.04 \mathrm{~cm} /$ month) in other populations such as Caucasians and Afri- 
Kinetics of methylmercury in humans

cans (Zareba et al., 2008). Also, the sample number in the current study was relatively small. Nonetheless, the mean hair-to-blood ratio of our study within the dynamic range was similar to recent studies (Berglund et al., 2005; Budtz-Jørgensen et al., 2004; Sakamoto et al., 2007), as described above. In addition, as maternal $\mathrm{MeHg}$ is selectively transferred to the fetus via the placenta (Sakamoto et al., 2010), such pregnant women were not included among our subjects. The measurement bias would have been minimized because the $\mathrm{T}-\mathrm{Hg}$ levels were not analyzed in all subjects until the end of the washout period. Thus, it is suggested that our findings were not heavily influenced by sampling, selection or measurement bias.

In conclusion, the hair-to-blood ratio of $\mathrm{MeHg}$ based on past studies appears to be underestimated in the light of recent studies. The crude half-life may be preferable to the recalculated one because of the practicability and uncertainties of the background level. If the hair-to-blood ratio and elimination constant are assumed to be 350 and 0.007 (= $\ln 2 / 100)$, respectively, the mean $\mathrm{T}-\mathrm{Hg}$ level of our subjects would be expected to be $36.6 \mathrm{ng} / \mathrm{g}$ in whole blood and $12.8 \mu \mathrm{g} / \mathrm{g}$ in hair, probably after 5-month $\mathrm{MeHg}$ intake of $3.4 \mu \mathrm{g} / \mathrm{kg} \mathrm{BW} /$ week, which is actually plausible as illustrated in Fig. 1.

\section{ACKNOWLEDGMENTS}

We thank all participants of this study. We would like to acknowledge Dr. Mineshi Sakamoto, National Institute for Minamata Disease, for his instructions on mercury analysis, and Ms. Mai Satoh, Environmental Health Sciences, Tohoku University Graduate School of Medicine, for her assistance with hair mercury analysis.

This work was supported by a grant from the Ministry of the Environment, Japan and by a grant-in-aid from the Japan Food Safety Commission (No. 0803). Funding sources had no role in the study protocol, in the collection, analysis, and interpretation of data, in the writing of the report, or in the decision to submit the paper for publication. For this reason, the findings and conclusions of this article are solely the responsibility of the authors and do not represent the official views of the above government agencies.

\section{REFERENCES}

Aberg, B., Ekman, L., Falk, R., Greitz, U., Persson, G. and Snihs, J.-O. (1969): Metabolism of methyl mercury (203Hg) compounds in man. Arch. Environ. Health, 19, 478-484.

Akagi, H. and Nishimura, H. (1991): Specification of mercury in the environment. In: Advances in Mercury Toxicology (Suzuki, T., Imura, N. and Clarkson, T.W., eds). New York: Plenum Press,
53-76.

Al-Shahristani, H. and Shihab, K.M. (1974): Variation of biological half-life of methylmercury in man. Arch. Environ. Health, 28, 342-344.

Al-Shahristani, H., Shihab, K. and Al-Haddad, I.K. (1976): Mercury in hair as an indicator of total body burden. Bull. World Health Organ., 53, Suppl., 105-112.

Berglund, M., Lind, B., Björnberg, K.A., Palm, B., Einarsson, Ö. and Vahter, M. (2005): Inter-individual variations of human mercury exposure biomarkers: a cross-sectional assessment. Environ. Health, 4, 20.

Birke, G., Johnels, A.G., Plantin, L.O., Sjostrand, B., Skerfving, S. and Westermark, T. (1972): Studies on humans exposed to methyl mercury through fish consumption. Arch. Environ. Health, 25, 77-91.

Budtz-Jørgensen, E., Grandjean, P., Jørgensen, P.J., Weihe, P. and Keiding, N. (2004): Association between mercury concentrations in blood and hair in methylmercury-exposed subjects at different ages. Environ. Res., 95, 385-393.

Dakeishi, M., Nakai, K., Sakamoto, M., Iwata, T., Suzuki, K., Liu, X.-J., Ohno, T., Kurosawa, T., Satoh, H. and Murata, K. (2005): Effects of hair treatment on hair mercury -The best biomarker of methylmercury exposure? Environ. Health Prev. Med., 10, 208212.

EFSA (European Food Safety Authority) (2004): Opinion of the Scientific Panel on Contaminants in the Food Chain on a Request from the Commission Related to Mercury and Methylmercury in Food. EFSA J., 34, 1-14. Available at http://www.efsa.europa.eu/ en/scdocs/doc/34.pdf [Accessed 25 September 2011]

Gosselin, N.H., Brunet, R.C., Carrier, G., Bouchard, M. and Feeley, M. (2006): Reconstruction of methylmercury intakes in indigenous populations from biomarker data. J. Expo. Sci. Environ. Epidemiol., 16, 19-29.

Grandjean, P., Weihe, P., White, R.F., Debes, F., Araki, S., Yokoyama, K., Murata, K., Sørensen, N., Dahl, R. and Jørgensen, P.J. (1997): Cognitive deficit in 7-year-old children with prenatal exposure to methylmercury. Neurotoxicol. Teratol., 19, 417-428.

Grandjean, P., Murata, K., Budtz-Jørgensen, E. and Weihe, P. (2004): Cardiac autonomic activity in methylmercury neurotoxicity: 14-year follow-up of a Faroese birth cohort. J. Pediatr., 144, 169-176.

Hislop, J.S., Collier, T.R., White, G.F., Khathing, D.T. and French, E. (1983): The use of keratinised tissues to monitor the detailed exposure of men to methyl mercury from fish. In: Chemical Toxicology and Clinical Chemistry of Metals (Brown, S.S., Savory, J. eds.), New York: Academic Press, 145-148.

Japan Food Safety Commission (2005): Food Safety Risk Assessment Related to Methylmercury in Seafood. Available at http:// www.fsc.go.jp/english/topics/methylmercury_risk_assessment. pdf [accessed 25 September 2011]

JECFA (Joint Food and Agriculture Organization/World Health Organization Expert Committee on Food Additives) (2003): Summary Report of the Sixty-first JECFA Meeting. Available at http://www.who.int/entity/ipcs/food/jecfa/summaries/en/summary_61.pdf [accessed 25 September 2011]

Kershaw, T.G., Clarkson, T.W. and Dhahir, P.H. (1980): The relationship between blood levels and dose of methylmercury in man. Arch. Environ. Health, 35, 28-35.

Legrand, M., Feeley, M., Tikhonov, C., Schoen, D. and Li-Muller, A. (2010): Methylmercury blood guidance values for Canada. Can. J. Public Health, 101, 28-31.

Mahaffey, K.R., Annest, J.L., Roberts, J. and Murphy, R.S. (1982): 
K. Yaginuma-Sakurai et al.

National estimates of blood lead levels: United States, 19761980: association with selected demographic and socioeconomic factors. N. Engl. J. Med., 307, 573-579.

Miettinen, J.K., Rahola, T., Hattura, T., Rissanen, K. and Tillander, M. (1971): Elimination of ${ }^{203} \mathrm{Hg}$-methylmercury in man. Ann. Clin. Res., 3, 116-122.

Mottet, N.K., Body, R.L., Wilkens, V. and Burbacher, T.M. (1987): Biologic variables in the hair uptake of methylmercury from blood in the Macaque monkey. Environ. Res., 42, 509-523.

Murata, K. and Yano, E. (2002): Medical Statistics for EvidenceBased Medicine with SPBS User's Guide [in Japanese]. Tokyo: Nankodo Publishers.

Murata, K., Dakeishi, M., Shimada, M. and Satoh, H. (2007): Assessment of intrauterine methylmercury exposure affecting child development: messages from the newborn. Tohoku J. Exp. Med., 213, 187-202.

National Research Council (2000): Toxicological Effects of Methylmercury. National Academy Press, Washington DC, USA, pp. $1-344$.

O'Flaherty, E.J., Hammond, P.B. and Lerner, S.I. (1982): Dependence of apparent blood lead half-life on the length of previous lead exposure in humans. Fundam. Appl. Toxicol., 2, 49-54.

Ohba, T., Kurokawa, N., Nakai, K., Shimada, M., Suzuki, K., Sugawara, N., Kammeo, S., Satoh, C. and Satoh, H. (2008): Permanent waving does not change mercury concentration in the proximal segment of hair close to scalp. Tohoku J. Exp. Med., 214, 69-78.

Rabinowitz, M.B., Wetherill, G.W. and Kopple, J.D. (1976): Kinetic analysis of lead metabolism in healthy humans. J. Clin. Invest., 58, 260-270.

Sakamoto, M., Kaneoka, T., Murata, K., Nakai, K., Satoh, H. and Akagi, H. (2007): Correlations between mercury concentrations in umbilical cord tissue and other biomarkers of fetal exposure to methylmercury in the Japanese population. Environ. Res., 103, 106-111.

Sakamoto, M., Murata, K., Kubota, M., Nakai, K. and Satoh, H. (2010): Mercury and heavy metal profiles of maternal and umbilical cord RBCs in Japanese population. Ecotoxicol. Environ. Safe., 73, 1-6.

Sherlock, J., Hislop, J., Newton, D., Topping, G. and Whittle, K. (1984): Elevation of mercury in human blood from controlled chronic ingestion of methylmercury in fish. Hum. Toxicol., 3, 117-131.

Smith, J.C., Allen, P.V., Turner, M.D., Most, B., Fisher, H.L. and Hall, L.L. (1994): The kinetics of intravenously administered methyl mercury in man. Toxicol. Appl. Pharmacol., 128, 251-
256.

Smith, J.C. and Farris, F.F. (1996): Methyl mercury pharmacokinetics in man: a reevaluation. Toxicol. Appl. Pharmacol., 137, 245252.

Snedecor, G.W. and Cochran, W.G. (1967): Statistical Methods. Ames: Iowa State University Press.

Stern, A.H. (2005): A revised probabilistic estimate of the maternal methyl mercury intake dose corresponding to a measured cord blood mercury concentration. Environ. Health Perspect., 113, 155-163.

Strain, J.J., Davidson, P.W., Bonham, M.P., Duffy, E.M., StokesRiner, A., Thurston, S.W., Wallace, J.M., Robson, P.J., Shamlaye, C.F., Georger, L.A., Sloane-Reeves, J., Cernichiari, E., Canfield, R.L., Cox, C., Huang, L.S., Janciuras, J., Myers, G.J. and Clarkson, T.W. (2008): Associations of maternal longchain polyunsaturated fatty acids, methyl mercury, and infant development in the Seychelles child development nutrition study. Neurotoxicology, 29, 776-782.

Suzuki, K., Nakai, K., Sugawara, T., Nakamura, T., Ohba, T., Shimada, M., Hosokawa, T., Okamura, K., Sakai, T., Kurokawa, N., Murata, K., Satoh, C. and Satoh, H. (2010): Neurobehavioral effects of prenatal exposure to methylmercury and PCBs, and seafood intake: neonatal behavioral assessment scale results of Tohoku Study of Child Development. Environ. Res., 110, 699704.

Task Group on Metal Accumulation (1973): Accumulation of toxic metals with special reference to their absorption, excretion and biological half-times. Environ. Physiol. Biochem., 3, 65-107.

US EPA (Environmental Protection Agency) (2001): Water Quality Criterion for the Protection of Human Health: Methylmercury, Final. EPA-823-R-01-001. Available at http://www.epa.gov/ waterscience/criteria/methylmercury/document.html [accessed 25 September 2011]

WHO (World Health Organization) (1976): Mercury. In Environmental Health Criteria 1. WHO, Geneva, Switzerland.

WHO (World Health Organization) (1990): Methylmercury. In Environmental Health Criteria 101: WHO, Geneva, Switzerland. Yaginuma-Sakurai, K., Murata, K., Shimada, M., Nakai, K., Kurokawa, N., Kameo, S. and Satoh, H. (2010): Intervention study on cardiac autonomic nervous effects of methylmercury from seafood. Neurotoxicol. Teratol., 32, 240-245.

Zareba, G., Cernichiari, E., Goldsmith, L.A. and Clarkson, T.W. (2008): Validity of methyl mercury hair analysis: mercury monitoring in human scalp/nude mouse model. J. Appl. Toxicol., 28, 535-542. 